\title{
ИННОВАЦИОННЫЕ БИЗНЕС-МОДЕЛИ
}

\author{
(c) 2020 Удальцова Наталья Леонидовна \\ кандидат экономических наук, доцент департамента Менеджмента и инноваций, \\ факультет «Высшая школа управления» \\ Финансовый университет при Правительстве Российской Федерации, Россия, Москва \\ E-mail: udaltsova.nl@yandex.ru
}

В статье рассматривается сущность инновационного бизнес-моделирования и ее актуальность на современном этапе развития предпринимательства. Исследованы факторы, определяющие эффективность инновационных бизнес-моделей. Автором определены основные типы инновационных бизнес-моделей и проанализирована российская практика развития инновационного бизнесмоделирования.

Ключевые слова: бизнес-модели, инновации, инновационные бизнес-модели

\section{Введение}

Одна из крупнейших нереализованных возможностей в организациях - это полноценное использование идей и знаний для трансформации бизнес-процессов в непрекращающийся процесс создания инноваций. Процессы, происходящие на глобальном рынке вынуждают компании переосмысливать деловые инновации и осуществлять исследовательскую деятельность для повышения конкурентоспособности. Это вносит значительный вклад в повышение производительности и качества предприятия, неотъемлемых компонентов бизнес-стратегии и успеха.

В этой связи значимость инноваций многократно возрастает. Новое время требует новых решений и управленческих моделей. Ценность имеет тот, кто быстрее внедрил и адаптировал свой бизнес и свои продукты под запросы клиента. Скорость принятия решений, время вывода новых продуктов на рынок, открытость компаний к взаимодействию с предпринимательским сообществом, научными организациями и другими крупными компания не менее важны, чем фундаментальная наука и собственные исследования. Новые технологии проникают в этот бизнес с невероятной скоростью. Быстрота реагирования компаний на их появление и оптимизация операционных бизнес-моделей в этой связи становятся все более мощным инструментом в конкурентной борьбе. В нынешнем мире цифровой трансформации главная цель любой компании, претендующей на лидерство,-двигаться быстрее рынка [1].

\section{Основная часть}

При исследовании взаимосвязи между бизнес-моделями и результатами деятельности компании возникает вопрос, связанный с инновационным процессом в бизнес-моделях. Мы знаем, что бизнес-модели являются динамичными структурами, которые должны изменяться, совершенствоваться и модернизироваться время от времени, чтобы обеспечить конкурентоспособность и выживаемость компаний на рынке. И именно здесь возникает закономерный вопрос: «Когда изменение в бизнес-модели материализуется в форме инновационного продукта?». За последние годы были предприняты попытки анализа и исследования некоторых аспектов инноваций в бизнес-моделях, а именно: специфика инновационного процесса, факторы влияющие на инновационную деятельность в компании, формирование бизнесмодели, преобразованной инновациями и др.

Очевиден тот факт, что в современной экономике власть на рынке полностью принадлежит потребителю, и это, безусловно, учитывается при построении бизнес-модели. В свою очередь, бизнес-модель должна быть нацелена на создание потребительской ценности покупателя. Такая ценность придает компании значительные конкурентные преимущества. Потребительская ценность создается на основе инноваций. Инновация - залог лидирующих позиций на рынке. Инновация - это не только какая-либо разработка, новый продукт или услуга, но и управленческий проект, так как, помимо разработки нового продукта важным пунктом является эффективное использование иннова- 
ции и управление ею. Кроме того, инновациясовокупностью процессов, которые охватывают всю деятельность компании и реализуются в виде новых видов услуг, продукции, технологий социально-экономических и организационнотехнических управленческих решений административного, экономического, производственного и другого характера. На инновационных бизнес-моделях строится бизнес современного рынка. И именно она является главным фактором успеха современного бизнеса.

Инновационная бизнес-модель - это специальный подход к выбору действий, предпринимаемых компанией и ее владельцами к распределению риска и дохода на стадии реализации инноваций и коммерциализации с целью получения максимальной отдачи от инвестиций, которые были вложены в инновации, это инструмент, соединяющий технические решения с финансово-экономическими результатами. Другими словами, инновационная бизнес-модель это соединение различных факторов бизнеса (труд, материальные ресурсы, капитал) в цепочку создания стоимости нового продукта и организации как таковой.

Суть инновационной бизнес-модели заложена в логике знаменитого американского ученого Генри Чесбро: «В самой инновации и технологии никакой внутренней ценности нет. Ценность инновации определяется бизнес-моделью, с помощью которой она выходит на рынок».

Многие успешные бизнесы начинались не с совершенного высокотехнологичного продукта, а с инновационной бизнес-модели:

- Amazon является крупнейшим в мире интернет-магазином, при этом, не имеет ни одного физического традиционного магазина;

- Apple Music (дочерняя компания Apple) крупнейший продавец музыки, при этом, не продает компакт-диски и не владеет ни одной студией;

- Skype - телекоммуникационный провайдер-гигант, не владеет собственной сетевой инфраструктурой;

- Netflix - мировой лидер, предоставляющий различные видео/фильмы на своей интернет-площадке не имеет ни одного физического традиционного магазина;

- Starbucks - кофейня мирового масштаба, которая продает обычный кофе по высоким ценам.

Поэтому основной принцип инновационной бизнес-модели гласит о том, что модель должна быть нацелена на управление цепочкой создания инновационной стоимости (Рисунок 1).

Согласно проведенному в США в 2017 году

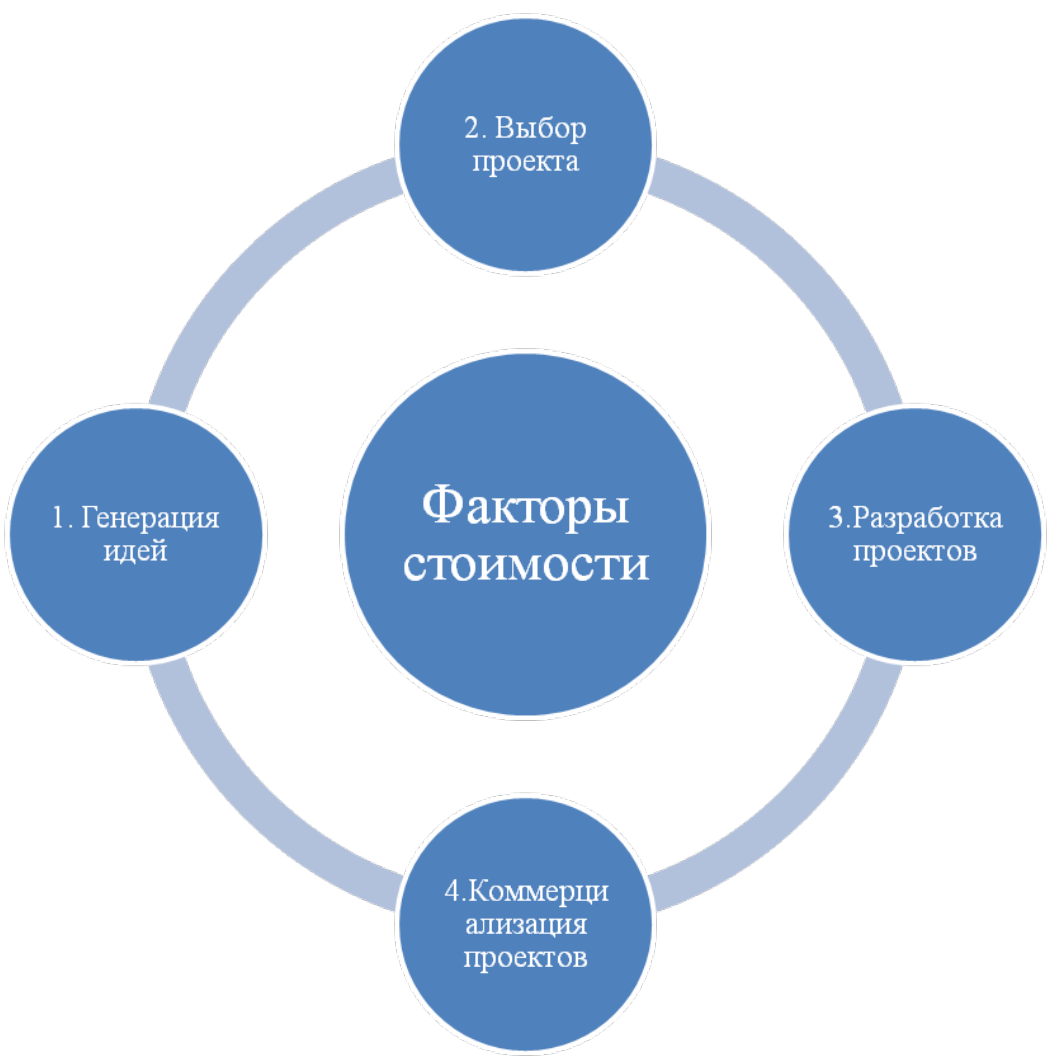

Рисунок 1. Цепочка создания инновационной стоимости проекта 
анализу консалтинговой группы Economist Intelligence Unit, 50\% менеджмента ставят в приоритете использование инновационных бизнес-моделей для развития компаний, нежели инновационные товары и услуги. Такой же результат показал анализ глав корпораций, проведенный IBM в 2018 г. опрос [2]. Большая часть руководителей корпораций отметило, что с учетом глобальных изменений, новых условий бизнеса, порождаемых мировым экономическим кризисом, необходимо менять бизнес-модель. По словам Г. Чесборо - знаменитого американского ученого-экономиста в сфере управления инновациями, «бизнес-модели компаний будут определять тот мир, в котором они станут конкурировать в XXI в.» [3]. Существует множество примеров успешного применения инновационных бизнес-моделей. Однако важно понимать, что у данных компаний не было главной целью опередить конкурентов на уже завоеванном и сложившимся рынке, а эти компании предлагали и использовали инновационные методы для предложения аналогичных товаров и услуг на рынке. В первую очередь, это компании McDonald's, FedEx, Dell Computers, Amazon, IKEA, Skype, Southwest, eBay, Starbucks, Wal-Mart, Groupon и прочие.

Southwest - компания, которая создала новую рыночную нишу - впервые выделила сегмент бюджетных. Dell Computers изменили свою модель поведения и предпочли доносить продукт напрямую конечному покупателю до потребителя, исключая посредников. Технологические инновации в интернет-продажах помогли Amazon создать новое рыночное пространство. Акцент был смещен в сторону увеличения ассортимента, низкой цены, скорость оформления заказов. Стоит отметить, что все вышеперечисленные компании использовали разные типы инновационной бизнес-модели. Однако, учитывая опыт упомянутых компаний, можно сделать главный вывод. Инновации должны быть основной силой для компании, придавать импульс ее инновационного развития, но инновации должны приниматься не как основа инновационной стратегии компании, а как средство, с помощью которого компания завоевывает новых клиентов и успешно реализует свою бизнес-модель.

Существуют три основных типа инновационной бизнес-модели [4]: интеграция, дирижирование, лицензирование. Данные типы имеют свои преимущества, недостатки и особенно- сти. Стоит отметить, что бывают случаи, когда крупные высокотехнологичные компании для увеличения окупаемости инвестиций успешно использовали в своей деятельности одновременно все типы бизнес-модели. При этом, если требуется, компании могут переходить с одной бизнес-модели к другой, согласно изменениям конъюнктуры рынка и изменениям, происходящим внутри самой компании.

Традиционная модель, которую так часто используют в инновационном бизнесе - это модель интеграции. В данной модели компания стремится контролировать все факторы, влияющие на результативность инновационного процесса, доходность и прибыльность от инноваций. Помимо прочего выбор модели обусловлен нежеланием компании делить потенциальный доход от коммерциализации продукта, в случае привлечения к бизнесу партнеров. Еще один фактор, оказывающий влияние на выбор в сторону модели интеграции лежит в плоскости интеллектуальной собственности и проектной информации, связанной с разработкой новшества. Передача и разглашение информации об интеллектуальных разработках, а также выстраивание партнерских отношений с другими потенциально заинтересованными в инновационном процессе компаниями является рисковым процессом для компании-разработчика. Однако это не минимизирует возможность сотрудничества с партнерами, поставщиками, продавцами и другими компаниями.

С одной стороны, используя модель интеграции, компания имеет полный контроль над интеллектуальными, материальными и финансовыми ресурсами, которые при эффективном управлении способны преобразоваться в конкурентные преимущества с возможностью получения дохода в полном объеме, с другой стороны, компания, используя эту модель несет значительные затраты и высокие риски в случае неверного прогнозирования рыночного спроса или не востребованности инновационного продукта на рынке (поскольку компания является основным инвестором в собственном инновационном проекте). Модель интеграции, как мы понимаем, свойственна крупным компаниям, финансово независимым и располагающими достаточным объемом финансовых ресурсов и производственными мощностями, а также не желающих делиться ценными знаниями с прочими компаниями с целью сохранения полной 
власти и контроля над инновационным проекTOM.

Для компаний, готовых разделить риски среди своих партнеров по причине отсутствия достаточного количества ресурсов для разработки нового продукта, существуют своя модель - модель дирижирования [5]. Модель дирижирования ориентирована на формирование партнерских отношений с заинтересованными в инновационном проекте компаниями, с целью разделения и уменьшения рисков, связанных с коммерциализацией нового продукта. Данная модель подразумевает разделение не только инновационных рисков, но и разделение будущего потенциального дохода с партнером. При этом мы должны понимать, что применение данной модели подразумевает пользование технологическими возможностями и ресурсами партнера, обеспечивается обоюдный доступ к ноу-хау и знаниям.

При этом существует опасность применения данной модели сотрудничества. Во время сотрудничества компания делится с партнером уникальными знаниями и, возможны случаи организации собственного бизнеса партнерами на том же рыночном пространстве. Чтобы уменьшить и предотвратить риски, компания должна заранее понять, какие этапы инновационной деятельности будут разработаны собственными силами, а какие будут отданы партнерам, заранее согласовать с партерами распределение инвестиций, прибыли, издержек и рисков. При правильной организации модель в состоянии менять продукт уже на этапах реализации и коммерциализации с учетом изменения рыночных условий или поведения конкурентов, в то же время обеспечивая гибкость организации, что очень важно в постоянно меняющихся условиях внешних среды. Модель дирижирования согласуется с моделью «открытых инноваций» и требует существенно меньших затрат за счет передачи финансовых рисков и делегирования полномочий внешним компаниям. Модель дирижирования применяется в узкоспециализированных и высокопрофессиональных компаниях, которые располагают необходимыми достаточными ресурсами, знаниями и умениями, а также желающие сотрудничать с другими компаниями.

Согласно международному опыту, в последнее время большая часть компаний используют модель лицензирования - именно данная модель способствует возврату потраченных средств компаниями, инвестированных в разработку новшества. Лицензирование мы можем определить, как механизм, через который осуществляется коммерциализация технологий, ноу-хау, услуг. При выборе данной модели компании способны сразу осуществить возврат своих вложений в полном объеме, которые были направлены в разработку новшества ранее, а также получить прибыль от интеллектуальных активов за счет использования этих активов другими компаниями, не вкладывая капитал в их реализацию и коммерциализацию [6]. При грамотном подходе менеджмента модель лицензирования может быть высокодоходным и низкозатратным бизнесом. Модель лицензирования является формой модели «открытых инноваций». Компании, действующие в рамках модели «открытых инноваций», в большинстве случаев применяют модель для увеличения рынков сбыта своих ноу-хау, в силу того, что один и тот же высокотехнологичный актив может использоваться на разных сегментах рынках для производства различных видов продуктов.

Безусловно, каждая компания выбирает для себя подходящую бизнес-модель, основываясь на возможностях компании и объеме инвестиций.

Все существующие бизнес-модели и иные процессы компании, вследствие постоянной изменчивости потребительских предпочтений и бизнес-среды, должны подвергаться регулярной оценке и совершенствоваться. Согласно мировому опыту, и как правилу, опыту ведущих компаний мира, для обретения устойчивости и финансовой стабильности в условиях постоянно меняющейся внешней среды компании вынуждены заниматься поиском и разработкой собственной инновационной бизнес-модели, которая способна поддерживать уровень конкурентоспособности на рынке. Использование инновационных бизнес-моделей способствует значительному развитию компаний, но, на практике добиться этого совсем нелегко.

Существует несколько шагов, с которых следует начинать создание эффективной модели управления инновациями:

- определить ответственных за внедрение инноваций, адаптировать текущую организационную структуру и основные бизнес-процессы компании с учетом инновационных целей, стоящих перед компанией;

- адаптировать бизнес-процессы управле- 
Таблица 1. Типы инновационных бизнес-моделей

\begin{tabular}{|c|c|c|c|}
\hline & \multicolumn{3}{|c|}{ Тип инновационной бизнес-модели } \\
\hline Характеристика & Интеграция & Дирижирование & Лицензирование \\
\hline \multirow{4}{*}{ Причины применения } & $\begin{array}{l}\text { Желание самостоятельно } \\
\text { вести инновационный } \\
\text { процесс }\end{array}$ & $\begin{array}{l}\text { Компания не имеет } \\
\text { специальных возможно- } \\
\text { стей и желаний вклады- } \\
\text { вать средства в развитие } \\
\text { идеи }\end{array}$ & $\begin{array}{l}\text { Использование данной } \\
\text { модели в качестве борьбы } \\
\text { с конкурентами }\end{array}$ \\
\hline & $\begin{array}{l}\text { Уверенность в успешной } \\
\text { реализации собственного } \\
\text { проекта }\end{array}$ & $\begin{array}{l}\text { Компания занимает но- } \\
\text { вый рынок }\end{array}$ & $\begin{array}{l}\text { Получение денег за ли- } \\
\text { цензирование и нежела- } \\
\text { ние заниматься реализа- } \\
\text { цией своих идеи }\end{array}$ \\
\hline & $\begin{array}{l}\text { Желание самостоятельно } \\
\text { и единолично владеть и } \\
\text { управлять разработками }\end{array}$ & $\begin{array}{l}\text { Компания доверяет дру- } \\
\text { гим лицам }\end{array}$ & \\
\hline & $\begin{array}{l}\text { Нежелание нести риск, } \\
\text { связанный с привлечени- } \\
\text { ем к процессу других лиц }\end{array}$ & $\begin{array}{l}\text { Компания хочет разде- } \\
\text { лить риски с другими }\end{array}$ & \\
\hline \multirow{3}{*}{ Преимущества } & Большой доход & Приобретение умений & Приобретение умений \\
\hline & \multirow{2}{*}{$\begin{array}{l}\text { Владение уникальными } \\
\text { специальными знаниями } \\
\text { как результата самосто- } \\
\text { ятельного управления } \\
\text { всеми этапами процесса }\end{array}$} & $\begin{array}{l}\text { Увеличение жизненных } \\
\text { сил компании }\end{array}$ & $\begin{array}{l}\text { Увеличение жизненных } \\
\text { сил компании }\end{array}$ \\
\hline & & Усиление бренда & Усиление бренда \\
\hline \multirow{2}{*}{ Риски } & Высокие затраты & $\begin{array}{l}\text { Высокие риски (самая } \\
\text { рискованная модель) }\end{array}$ & $\begin{array}{l}\text { Лицензия не гарантирует } \\
\text { успех на рынке, нежели } \\
\text { патента }\end{array}$ \\
\hline & Высокие риски & Утечка информации & $\begin{array}{l}\text { Трудности в удержании } \\
\text { прав на интеллектуаль- } \\
\text { ную собственность }\end{array}$ \\
\hline $\begin{array}{l}\text { Примеры успешного при- } \\
\text { менения модели }\end{array}$ & $\begin{array}{l}\text { Citibank, Intel, Tayota, } \\
\text { BMW, Zara }\end{array}$ & Boing, Apple, Microsoft & $\begin{array}{l}\text { Motorola, Bosch, Nokia, } \\
\text { IBM, }\end{array}$ \\
\hline
\end{tabular}

Источник: В.А. Сикацкий, Е.А. Курепина «Инновационная бизнес-модель как фактор достижения конкурентного преимущества фирмы»/ Управленческое консультирование, № 3, 2010

ния инновационными проектами;

- выстроить взаимодействие с внешней средой и внедрить инструменты управления внутренними и внешними инновациями;

- внедрить новые подходы и методики управления инновационными проектами.

Во многом определяют эффективность работы с инновациями следующие основные факторы:

- Снятие барьеров и ускорение процессов;

- Выделение финансовых ресурсов на инновационное развитие и реализацию проектов;

- Выделение человеческих и организационных ресурсов на инновационное развитие.

Если компания повышает скорость внедрения внутренних и внешних инноваций, она имеет возможность пользоваться следующими преимуществами:

- дополнительная прибыль от реализации за счет более своевременного вывода продукта или решения на рынок;

- экономический эффект за счет внедрения новой технологии или бизнес-процесса, повышающих операционную эффективность;

- более эффективное взаимодействие с внешними инновациями.

Если компания рассчитывает на внедрение внешних решений и работе со стартапами, эффективные внутренние процессы являются одним из важных факторов успешности данной деятельности. Следует помнить, что любая инновационная деятельность сопряжена с рисками ошибок и убытков, однако в большинстве компаний отсутствуют необходимые методы ощутимого вознаграждения и поощрения сотрудников за инновационную деятельность. Для преодоления этой проблемы следует выстраивать положительный характер мотивации и 
четко разграничивать, когда она должна мотивировать на эксперимент, а когда мотивировать на достижение четкого финансового результата. При этом уровень вознаграждения за инновационную деятельность должен строиться на долгосрочных принципах, охватывать всех участников инновационного процесса и быть для них финансово значимым.

Российская современная практика использования инновационных бизнес-моделей находится только на этапе своего становления. К сожалению, повышение конкурентоспособности бизнеса с учетом использования инноваций для российских предпринимателей является непопулярным методом. Согласно проведенному опросу Институтом экономики переходного периода в 2014 году 61\% российских предпринимателей поддержали инновационный путь развития, но уже в 2018 году - только 51\% российских предпринимателей [7]. Главная причина данной неутешительной ситуации - рисковая инновационная деятельность.

По данным официального издания «Россия в цифрах» Федеральной службы государственной статистики, в 2018 году только 12,8\% компаний России вели инновационную деятельность, стоит отметить, что высокотехнологические инновации внедрялись лишь в 9,9\% компаний России. Доля внутренних затрат на развитие инноваций аналогично низкая и составляет $1,1 \%$ от ВВП России (34 место в мире). К сведению, данный показатель в Израиле, Южной Корее, Швейцарии, Швеции колеблется в диапазоне 3-4\% ВВП [8]. Кроме того, наблюдается сокращение финансирования НИОКР с 2013, а прогноз на 2019-2020 годы Министерства экономического развития РФ также предполагает незначительное сокращение данных инвестиций в науку. При всем этом, Россия является лидером занятости в науке: 429,9 тысяч человек в 2018 году (4 место в мире) [9].

Исходя из нашей специфической практики и стадии развития экономики России, современный российский бизнес становится рентабельнее благодаря вложениям не в инновации, а в маркетинг. После мирового финансового кризиса, который привел к росту стоимости ресурсов, кредита, жизнь компаний, использующие инновации в качестве рычага своего развития усложнилась еще больше. Поэтому большинство рос- сийских компаний предпочитает не рисковать.

Российские инвестиции в НИОКР по сравнению с мировой практикой даже в успешных крупных российских компаниях слишком малы. Кроме того, доля финансирования научных внутренних исследований и разработок корпораций в России год за годом снижается, при этом, зарубежом отмечается постоянный рост [10]. Даже учитывая тот факт, что значительно увеличилось финансирование российских исследований и разработок из федерального бюджета, к сожалению, такое же пропорциональное увеличение отдачи от инвестиций не произошло. Кроме того, даже учитывая постоянную поддержку инноваторов государством, к сожалению, в последние годы снижается число вновь создаваемых стартапов и малых высокотехнологичных компаний, а существующие длительное время инновационные компании находятся в перманентной стагнации [11].

\section{Заключение}

Анализируя инновационную активность российских компаний, можно сделать вывод, что низкая конкуренция в большинстве отраслях России блокирует развитие инноваций в компаниях (исключение - сектор мобильной связи и розничная торговля). Кроме того, слабая финансовая система России негативным образом влияет на развитие инновационного процесса компании.

Инновация будет успешна в том случае, если спрос, общественные потребности и предложения высокотехнологичных изобретений совпадут. Стоит отметить, что у каждой вышеперечисленной составляющей своя логика развития. Одна из главных причин медленного развития высоких технологий в России является низкая емкость российского рынка высокотехнологичных продуктов. При этом, по мнению российских экономистов, недофинансированный спрос и, как правило, со стороны крупной промышленности, является значительным барьером в развитии инноваций в российском бизнесе [11]. Все эти неприятные утверждения объясняются, в первую очередь, нехваткой ресурсов у компаний на инновации, не востребованностью высоких технологий в силу того, что во многих отраслях отсутствует конкуренция и самой структурой российской экономики. 


\section{Библиографический список}

1. https://cio.ru/articles/211018-Voronka-innovatsiy-v-X5-Retail

2. Джонсон М., Кристерсен К., Кагерманн Х. Обновление бизнес-модели// HarvardBusinessReview Poccия, 2018 № 3 C 63-69.

3. Чесборо Г. У. Зачем компаниям открывать свои бизнес-модели// Вестник Санкт-Петербургского университета. Сев. Менеджмент, 2017, Вып. 4, С 91-115

4. Антропов М.С., Ломоносова М.В., Белолипецкий В.Г., КоростылеваИ.И. Современные инновационные стратегии и бизнес-модели компаний. [Электронный ресурс] // URL: http://www.msu.ru/projects/amv/doc/ h6_1_6_1_nom4_2.pdf

5. Шелехова Н. В. Инновационные бизнес-модели// Экономика и управление. Экономическое право. - 2016. № 7.- С. 81-84.

6. Эндрю Дж.П. Возврат на инновации: практическое руководство по управлению инновациями в бизнесе. Минск. 2015

7. Цукер В. Блохи на поток// Эксперт Северо-Запад 2018 № 36. С 20-22.

8. Федеральная служба государственной статистики - https://www.gks.ru/free_doc/doc_2018/rusfig/rus18.pdf

9. Международный статистический портал https://knoema.ru

10. Индикаторы инновационной деятельности: 2018. Статистический сборник ВшЭ https://www.hse.ru/ primarydata/ii

11. Имамутдинов И., Медовников Д., Розмирович С. Пройти пубертатный период// Эксперт, 2016 № 2 С. $61-64$ 